This item was submitted to Loughborough's Research Repository by the author.

Items in Figshare are protected by copyright, with all rights reserved, unless otherwise indicated.

\title{
Socially sensitive regulation for water services
}

PLEASE CITE THE PUBLISHED VERSION

PUBLISHER

(C) Thomas Telford Publishing

LICENCE

CC BY-NC-ND 4.0

\section{REPOSITORY RECORD}

Bateman, Jonathan S., M. Sohail, and Cyrus Njiru. 2019. "Socially Sensitive Regulation for Water Services". figshare. https://hdl.handle.net/2134/3887. 
This item was submitted to Loughborough's Institutional Repository (https://dspace.lboro.ac.uk/) by the author and is made available under the following Creative Commons Licence conditions.

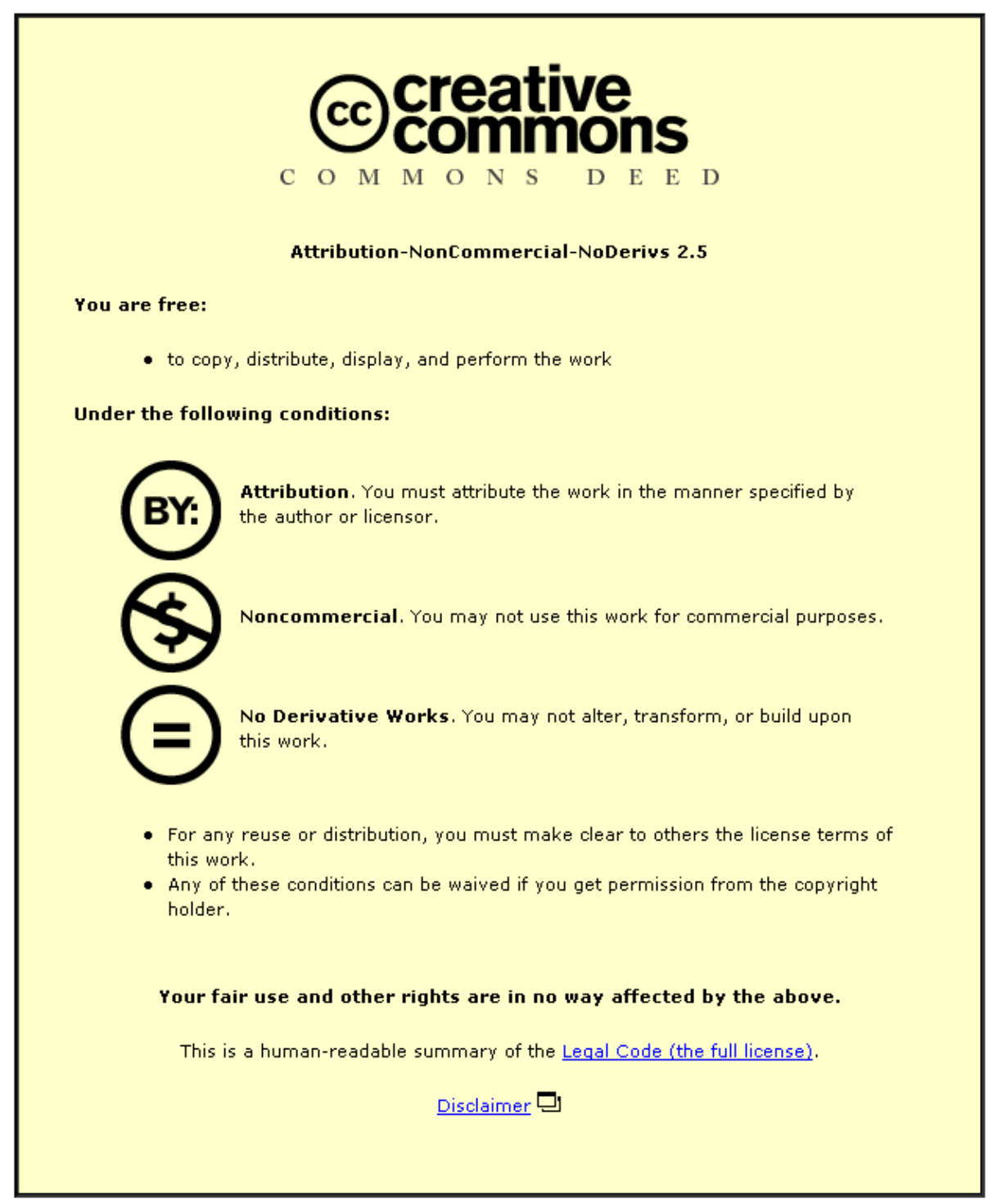

For the full text of this licence, please go to: http://creativecommons.org/licenses/by-nc-nd/2.5/ 


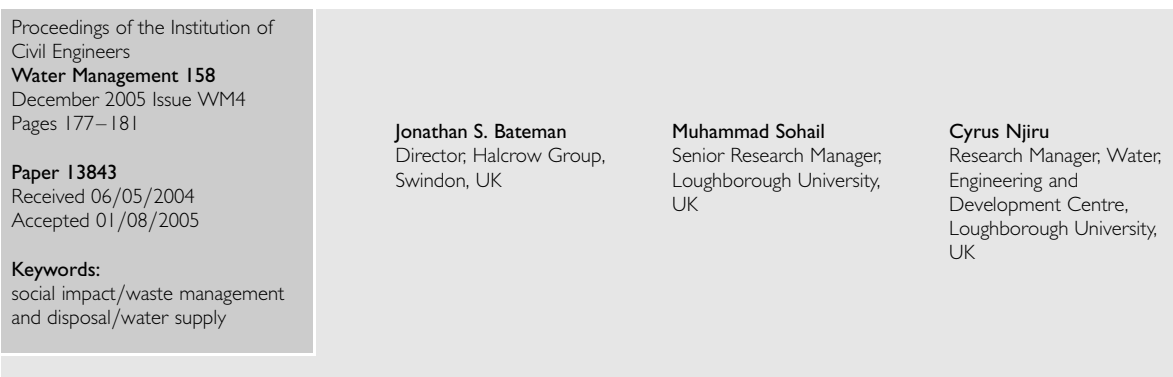

\section{Socially sensitive regulation for water services}

\section{J. S. Bateman, M. Sohail and C. Njiru}

The provision of essential services such as water and sanitation may be considered a first step towards social inclusion. The overall sustainability of water and sanitation services also depends on social considerations. This paper explores the relationship between the regulator and the utility in the context of service provision for low-income users. It presents a general background to regulation in the water sector, along with some of the challenges faced by governments and regulators when implementing private sector involvement. Drawing upon the authors' experience of water services management including regulation and private sector participation (PSP) in the water sector, the paper is based on a review of the literature, discussion with relevant professionals and an examination of a number of projects. The authors detail the role of the regulator and identify recurring themes relating to regulation and the poor. The shortcomings of specific projects are highlighted not as criticisms, but in the interest of sharing of knowledge and improving services to the poor in the long run. The paper includes suggestions on how regulation of water services could be undertaken in a low-income environment. The authors conclude that if water utilities are to perform in a socially sensitive manner, appropriate regulatory regimes are necessary.

\section{INTRODUCTION}

Many policymakers now see private sector participation (PSP) in water and sanitation as essential for improvement of efficiency and effectiveness, through the introduction of competition and profit motive in the sector. However, regulatory mechanisms are necessary to ensure that the desired objectives of PSP are achieved. Approaching, developing and then implementing regulatory mechanisms involve challenges, particularly in developing countries where the proportion of the poor is high and serving the poor is therefore crucial.

Regulation, which comprises a combination of command-control (stick and carrot) mechanisms and economic instruments (penalties and bonuses), creates a regime in which the emerging private sector performs effectively. It is a necessary component of any sector reforms and PSP in monopoly services as it aims to ensure the proper performance of obligations (on all sides) and protection of customers. Water customers comprise a wide spectrum of economic and social groups, each with differing needs, expectations and financial circumstances. Although the poor and other vulnerable customers may represent a small proportion of the (existing) customer base, they warrant a disproportionately large amount of regulatory attention if they are not to be marginalised. It should also be noted that low-income citizens comprise the majority of potential new customers, as governments and utilities seek to expand the water coverage in an attempt to meet the Millennium Development Goals (MDGs) agreed by the international community.

The transition from public to private sector delivery of any service changes the role of the public sector fundamentally. The current thinking that is driving water sector reforms in many developing countries is that the public sector should distance itself from direct service delivery, but instead act as standards setter, paymaster and supervisor of the private sector service providers through contractual arrangements. The private sector meanwhile assumes the public sector's former role in service delivery, the difference being that it must make a profit. Such sector reforms necessitate setting up of regulatory institutions that will supervise water service providers.

Setting up effective regulatory institutions and developing regulatory capacity can take a long time. In many developed countries, it has taken decades to develop effective regulation, yet the severity of poverty is much less of an issue than in developing countries. ${ }^{1}$ Several years are usually needed before the regulator is able to amass sufficient information-gathering capability and legal capacity to exert its influence effectively. In developing countries, information on services to low-income areas, which include many informal settlements, may be even harder to come by. Thus, despite its high priority, achieving improvements in the delivery of social obligations (such as serving the poor and protecting the vulnerable) can take several years. Indeed, despite the international attention directed at providing water and sanitation services to the poor, developing effective regulatory mechanisms to ensure that water utilities are financially sustainable while providing services to the poor will undoubtedly take a long time.

\section{A SUMMARY OF REGULATION}

Modern incentive-based regulation embraces pricing, service standards, future planning and long-term sustainability. It combines incentives, penalties and periodic rebasing of the initial contract conditions (licence) at the request of either party. The 
regulatory framework may also include controlling abuse of monopoly power and unfair discrimination between customers, while at the same time encouraging efficiency.

Underpinning regulatory effectiveness (irrespective of the sector) involves ensuring independence of action of the regulator and the absolute separation of the roles of service provider, regulator and political processes.

In the drive to attract private sector participation, the importance and the true value of regulation can be underestimated. Private involvement is defined inevitably by contracts and the early regulatory regime invariably focuses on price-sensitive deliverables such as investment activity, enforcing service standards and payments to the private operator company. Only when these fundamentals are in balance can regulatory attention turn to protection of low-income groups.

\section{I. Scope of regulation}

Regulation in the water sector is necessarily wide-ranging and should cover all performance aspects of water services delivery. For each of the services provided, i.e. water supply (including water quality), wastewater (including environmental standards) and storm water, regulation should include the following

(a) setting or adjusting service prices

(b) monitoring performance in key areas and making interventions where necessary

(c) representing customers and taking up grievances with service providers

(d) assessing quality and environmental performance through monitoring and enforcement of standards

(e) representing national interests in connection with setting appropriate and affordable standards of service and determining an overall water and sanitation services strategy.

The provision of water services encroaches upon other governmental activities and responsibilities-public health, social welfare, the environment and general economic development, for example. In consequence governments may choose to combine regulation of several activities under a single umbrella. This facilitates an integrated approach to setting standards and fosters a close link between performance standards and prices. However, by definition such regulatory arrangements require considerable institutional capacity and can become cumbersome and bureaucratic.

Alternatively governments may create individual regulators for separate sectors. In some cases regulatory separation exists even within a sector, for instance by separating regulation of environmental and health standards from regulation of prices, standards and performance. While this approach may allow individual regulators to focus on specific issues, in the water sector it risks the pursuit of high-cost policies.

Finally where PSP is adopted locally on an ad hoc basis (for instance, where an individual municipality engages a private operator) regulation more closely resembles contract supervision or management rather than sector regulation. Such local regulators have to work within the ambit of other national regulators in relation to activities such as environmental protection, health or economic development. In these circumstances the utility may face regulation by several separate bodies.

To date water sector PSP in emerging economies has been implemented mainly on a local basis at municipal or regional level; hence this latter arrangement is more common. Arguably it is less capable of dealing with complex issues such as protecting poor customers than the single or cross-sector arrangements described earlier.

As far as services to the poor are concerned, the scope of economic regulation includes

(a) tariff setting through periodic price reviews or triggered by significant changes

(b) performance monitoring, including financial, operational and customer service issues

(c) payment of fees and incentives (or penalties) to the private company

(d) ensuring that the contractual provisions are met

(e) taking regulatory actions in the event of performance failure, including the settlement of disputes and termination in extremis

(f) monitoring service performance including expansion, new supplies, environmental compliance and issues relating to customer management or disconnection for non-payment.

\section{SETTING UP REGULATION IN A LOW-INCOME ENVIRONMENT}

This section identifies some of the key challenges faced by regulators (or contract supervisors) in setting up and administering PSP arrangements. Most of the cases relate to concession or management contracts under which regulation is effected locally through a contract framework as opposed to national policy. The section draws out some recurring messages from past projects and poses questions to a wider audience on how the challenges influence provision of services to the poor.

\section{I. The process of creating a new regulatory body}

The PSP contract becomes effective typically about two months after the conclusion of negotiations and award and signature of the contract(s), by which time the regulator must be up and running. The time lag is needed to establish legally and enable any joint ventures, to register the operating companies and to put the financial infrastructure for operations in place. Depending upon the scope and scale of the PSP, it is unlikely that two months is adequate.

By commencement, the regulator should be constitutionally established, legally enabled, adequately staffed and must have sufficient capacity to supervise the contract effectively. PSP arrangements usually require that most of the water utility's functions, staff and statutory obligations become the responsibility of the private operator; hence transition and ongoing operations are necessarily complex. Creating and resourcing the contract supervisor (regulator) is correspondingly demanding, particularly at inception. As a result, regulatory and institutional arrangements can vary widely between utilities. 
A large part of the regulator's responsibilities involve performance monitoring, payment certification and ensuring the proper development of the water services infrastructure (including extensions to provide services to low-income communities). In many cases it may share these responsibilities jointly with other government bodies such as a water resources agency or a planning agency.

\subsection{Information management}

Initially the operator will command considerably more information about the technical and commercial performance of the water services systems than the regulator. It takes time for the regulator to collect sufficient information to be on a level footing. This initial imbalance (known as 'information asymmetry') is widespread in all emerging regulatory regimes and can be particularly detrimental in low-income environments. It arises from the following reasons

(a) it can take two or three years (or much longer where assets are run down or service standards very poor) to plan and implement performance improvements

(b) the staff available to the regulator may be less experienced in regulatory processes than those of the operator (who may have considerable experience gained in similar contracts elsewhere)

(c) the onus for data gathering and reporting rests with the operator, while the regulator is confined to requesting and reviewing reports

(d) the regulator can assess performance only at a macro level, while the operator has access to management and commercial information for local areas

(e) there is little consistent cost and performance data in low-income environments, against which standards can be set or performance assessed.

The authors' experience of emerging regulatory regimes worldwide suggests that it could take up to five years or more before newly created regulators are able to acquire sufficient information to make a significant impact on the performance of operators or outcomes from the point of view of customers.

The problem of information asymmetry hampered regulatory effectiveness following water privatisation in the UK in 1989. In this case it took some ten years of regulatory monitoring, together with several political initiatives to exert regulatory pressure effectively. The question that arises is how can robust information on services for the poor be collected more expediently to reduce information asymmetry?

Private sector involvement in water services is growing rapidly in low-income environments, with PSP projects under consideration in Africa, Asia and Latin America. From the regulatory perspective, the African Development Bank in association with the Department for International Development has established a pan-African utility performance-benchmarking project. There could be merit in new regulators in Africa (and in other regions) accessing information from that project and developing a forum for sharing experiences. If this proves valuable there may be merit in adopting similar projects in other regions.

\subsection{Relationship between regulator and service providers}

It is widely accepted that effective regulation is essential to extract the full benefits of private sector participation in delivering water and environmental sanitation services. Such regulation requires a clear delineation of the roles and responsibilities of customers, the regulator and the private operator with transparent relationships between all parties.

Establishing these roles and relationships in an even-handed manner, while preserving independence and ensuring fairness to all parties can pose a particular challenge for the regulator. This challenge is heightened where regulation concerns a small number of single sector service providers. The regulators of such single sector operators may be open to criticism from one party or another for bias.

\subsection{Regulatory pitfalls}

From the authors' experience, there are a number of regulatory pitfalls where the relationship between the water services provider and the regulator may become too comfortable, poor, or where it may break down altogether.

\subsubsection{Bypassing the regulator. On a concession in Latin} America the private concessionaire bypassed the regulator in order to deal with government directly. As a consequence the credibility of the regulator has been undermined.

\subsubsection{Distrust of foreign management. A management} contract in the Caribbean was frustrated and terminated early owing to antagonism among members of the supervising board caused by the presence of a foreign private manager.

3.4.3. Lack of finance. One PSP arrangement failed because the promised donor funding did not materialise. This meant that the operator was unable to implement the investment programme.

\subsubsection{Failure of the state to fulfil its obligations. The} operator appointed for a PSP contract in an African country was unable to deliver the agreed performance improvements because the state-owned asset holding company failed to deliver its contractual commitment to fund the renewal of major plant.

3.4.5. Regulatory capture. Where the regulator's sphere of activity is confined to a single supplier, or where external pressure and accountability are absent, the regulator can become over-familiar with the interests of one party. An example of such an arrangement existed in southern Africa where the private operator (responsible for water distribution to consumers) depended upon bulk supplies from several state-owned water boards. The boards operated autonomously with little regulatory pressure and as effective monopolies with a free hand in setting tariffs and standards. This undermined the performance of the PSP operator.

\subsubsection{Micro-management. There are examples where the} regulatory/supervisory body has become involved too closely in day-to-day management of the utility. This hampers both the operator's progress and regulatory process. Furthermore, by blurring the role of 'provider' and 'client', the regulator may 
become unable to enforce the contractual requirements effectively.

3.4.7. Political interference. There is an inherent danger that political imperatives will come into conflict with the principles of good regulation. In the UK political imperatives have prevailed on several occasions.

\subsection{A delicate balancing act}

In practice a pragmatic balance has to be struck by the regulator between the various pressures. In the early days of a PSP regime the regulator should typically focus on the following key issues

(a) establishing a professional working relationship with the private operator that strikes a balance between antagonism and being involved too closely

(b) adhering to the legal and contractual powers and responsibilities described in the law, licence or contract, while at the same time focussing on key issues that affect customers and potential customers

(c) establishing numerical bases for determining whether levels of service are improving or getting worse

(d) reviewing and updating the operator's plan periodically to ensure that it is always relevant-especially in relation to connections, expansion and provision of new services (including those to low-income customers).

\section{STRATEGIC PLANNING OF WATER SERVICES}

In theory, the process of implementing PSP provides an opportunity for strategic planning of water services. However, the authors' experience in PSP in low-income environments suggests that such planning is not always effective. There may be insufficient data and a lack of expertise; this together with entrenched attitudes can result in crisis management rather than properly based strategic planning. The base-line plans upon which contracts are founded, therefore, are frequently ill informed or subject to many caveats such that they are unreliable.

\section{I. Updating strategic plans}

A further difficulty in strategic planning of water services is that such plans can become out of date very quickly owing to material changes in supply and/or demand, in demographics, service standards or operating cost. As a result, it is generally accepted that rolling plans are needed with a major update every three to five years.

This creates particular difficulties for regulators, as each revised plan has a cost and tariff implication requiring regulatory (and occasionally political) approval. Experience indicates that tariff negotiations present the greatest potential for political interference and disputes between the parties and can distract from issues such as service provision to low-income customers.

Key regulatory issues to be addressed in approving updated strategic plans and reviewing tariffs include

(a) achieving a balance between inflow and outflow of funds

(b) taking account of the amount of funding available from external sources (c) striking a balance between price increases and service enhancements or expansion

(d) setting achievable efficiency improvement targets over the period

(e) setting standards and establishing the cost impact of any service enhancements.

In assessing and approving updated strategic plans, the regulator may also need to recognise and adjust for the tendency of operators to seek fail-safe, reliable solutions at a higher-cost in preference to lower-cost (greater risk) alternatives. Unless corrected, this tendency can over-state prices and cause regulators to lower their horizons for service enhancements or expansion of services to low-income areas.

\section{PROJECTS ANALYSIS}

In order to gather more evidence on regulation and the poor the authors examined a number of past projects and noted recurring themes relating to services to the poor. Table 1 summarises the authors' findings.

\section{DISCUSSION AND CONCLUSIONS}

This paper has presented some general regulatory principles that seek to guarantee water and sanitation services for all including the poor. It also indicated how institutional and information constraints, together with an early focus on achieving a balanced water sector strategy, can distract regulatory attention from improving service provision in low-income areas.

The key regulatory functions that impact upon poor customers have been identified, and proposals made for necessary regulatory actions to promote improved water services to low-income customers.

\section{I. Planning}

(a) Participate in and provide information to other government agencies to develop a pro-poor water policy.

(b) Negotiate and agree with the regulated utilities appropriate service levels and priorities for service improvements in low-income areas.

(c) Develop a reporting regime for assessing the regulated utilities' progress against agreed targets.

(d) Promote competition and issue licences to new entrants or secondary providers.

(e) Periodically agree medium-term outputs, funding and tariffs with the regulated utilities.

( $f$ ) Capacity building for stakeholders, to empower them to negotiate with service providers.

\subsection{Enforcement}

(a) Monitor the regulated utilities' performance against agreed targets.

(b) Invoke regulatory actions in the event of performance failure.

(c) Apply incentive and penalty mechanisms to reflect the regulated utilities' progress in achieving targets.

(d) Liaise with other government agencies and support other initiatives for improving services to low-income areas. 


\begin{tabular}{|c|c|c|c|c|c|c|}
\hline No. & Project & $\begin{array}{l}\text { Is the regulator } \\
\text { independent? }\end{array}$ & $\begin{array}{l}\text { Is regulation } \\
\text { fixed to the } \\
\text { terms of the } \\
\text { PSP contract? }\end{array}$ & $\begin{array}{l}\text { Is there flexibility } \\
\text { for pro-poor } \\
\text { regulation? }\end{array}$ & $\begin{array}{l}\text { How is } \\
\text { information } \\
\text { gathered for } \\
\text { those without } \\
\text { a supply? }\end{array}$ & $\begin{array}{l}\text { What authority } \\
\text { does the regulator } \\
\text { have for } \\
\text { pro-poor issues? }\end{array}$ \\
\hline I & $\begin{array}{l}\text { Buenos Aires Water and } \\
\text { Sewerage Concession }\end{array}$ & Yes & Yes & 一 & $\begin{array}{l}\text { Part of 30-year } \\
\text { programme }\end{array}$ & $\begin{array}{l}\text { Needs } \\
\text { government } \\
\text { support }\end{array}$ \\
\hline 2 & $\begin{array}{l}\text { Guyana-water and } \\
\text { sanitation sector study }\end{array}$ & Yes & Yes & Not yet in place & Not yet in place & Not yet in place \\
\hline 3 & $\begin{array}{l}\text { Nigeria Water: PSP options } \\
\text { study }\end{array}$ & No & - & - & - & - \\
\hline 4 & $\begin{array}{l}\text { Greater Negombo (Sri } \\
\text { Lanka) water sector PSP }\end{array}$ & Yes & & \multicolumn{3}{|c|}{ Work on-going_-not yet defined } \\
\hline 5 & $\begin{array}{l}\text { Astana Water and } \\
\text { Environment } \\
\text { Development Project }\end{array}$ & Yes & No & Probably not & $\begin{array}{l}\text { Via elected } \\
\text { representatives }\end{array}$ & $\begin{array}{l}\text { Can limit charges } \\
\text { to poor } \\
\text { households }\end{array}$ \\
\hline 6 & $\begin{array}{l}\text { Zaparozhzhia Municipal } \\
\text { Water Service } \\
\text { Development, Ukraine }\end{array}$ & Yes & No & & & \\
\hline 7 & $\begin{array}{l}\text { Rostov-on-Don Strategic } \\
\text { Plan, Russia }\end{array}$ & Yes & No & & & \\
\hline 8 & $\begin{array}{l}\text { Chisinau Water and } \\
\text { Wastewater } \\
\text { Rehabilitation Project, } \\
\text { Moldova }\end{array}$ & Yes & No & & & \\
\hline 9 & $\begin{array}{l}\text { Ukraine Municipal Utilities } \\
\text { Development } \\
\text { Programme, Ukraine }\end{array}$ & Yes & No & & & \\
\hline
\end{tabular}

\subsection{Consultation}

(a) Actively engage with customers, including those in low-income areas, to assess and agree on service levels and priorities for implementing improvements.

(b) Consult with customers in low-income areas to ensure that standards reflect their needs and preferences.

(c) Consult with customers more generally over whether current standards are defined adequately and measured appropriately.

(d) Consult over whether prices reflect service levels and services delivered.

\subsection{Customer representation}

(a) Create mechanisms for effective customer representation

(b) Promote the interests of customers in low-income areas.

(c) Settle disputes between customers and the regulated utility.

(d) Protect customers by setting prices appropriate to service levels and services delivered.

In the context of private sector participation, the needs of the poor can be neglected and their voices not heard. An efficient and appropriate regulatory regime can ensure that low-income customers are socially included and given proper consideration.

\section{ACKNOWLEDGEMENTS}

Support from the Department for International Development (DFID) has enabled the authors to undertake this work. The research was a collaborative effort between the Water, Engineering and Development Centre, Loughborough University and Halcrow. The authors wish to thank A. J. Gale of Halcrow for his comments. The views expressed here are not necessarily those of DFID, Halcrow or WEDC.

\section{REFERENCE}

1. FARAdE T. and SoHAIL M. Making regulatory mechanisms work: lessons from cases of private sector participation. Water Policy, 2003, 5, No. 3, 269-288.

\footnotetext{
What do you think?

To comment on this paper, please email up to 500 words to the editor at journals@ice.org.uk

Proceedings journals rely entirely on contributions sent in by civil engineers and related professionals, academics and students. Papers should be 2000-5000 words long, with adequate illustrations and references. Please visit www.thomastelford.com/journals for author guidelines and further details.
} 